\title{
GNSS brings us back on the ground from ionosphere
}

Yang-Yi Sun ${ }^{*}(0)$

\begin{abstract}
Both solar activities from above and perturbations of Earth's surface and troposphere from below disturb ionospheric structure and its dynamics. Numerous ionospheric phenomena remain unexplained due to the complicated nature of the solar-terrestrial environment. We do appreciate the ground- and space-based Global Navigation Satellite System (GNSS) techniques being around and providing global observations with high resolutions to help us to resolve unexplained phenomena. This paper summarizes recent studies of the effect of solar (geomagnetic storm and total solar eclipse), tropospheric (typhoon, walker circulation, and El Niño-Southern Oscillation), and earthquake/tsunami activities (2010 Chile, 2011 Tohoku, and 2015 Nepal earthquakes) on the ionosphere utilizing the global ground-and space-based GNSS observations.
\end{abstract}

\section{Introduction}

The Earth's ionosphere is the ionized portion of the upper atmosphere at an altitudinal range from $\sim 60$ to thousands of kilometers that is central to our solar-terrestrial environment (Kamide and Chian 2007). Solar activities, such as solar flare, coronal mass ejection, and moon shadow of eclipse, induce rapid change of ionosphere morphology so-called ionospheric weather that significantly impacts radio communication and navigation systems.

The ground-based Global Navigation Satellite System (GNSS) receivers can measure the ionospheric total electron content (TEC) that routinely monitor global ionospheric climate and weather. The number of groundbased GNSS receiver increases significantly in the recent three decades. For example, 10 ground-based GNSS receivers in 1988, 450 receivers in 1998, and more than 2000 receivers after 2008 are freely available from the International GNSS Service (IGS) (http://www.igs. org). The dense ground-based GNSS TEC observations have been widely used to monitor the horizontal structure of ionospheric climate and weather with high temporal $(30 \mathrm{~s})$ and spatial resolutions (less than 1 degree in longitude and latitude). The dense TEC observations

\footnotetext{
*Correspondence: sunyy@cug.edu.cn

Institute of Geophysics and Geomatics, China University of Geosciences, Wuhan 430074, China
}

recorded regional ionospheric perturbations due to geomagnetic storm (Sun et al. 2013), eclipse (Liu et al. 2011), earthquake/tsunami (Liu et al. 2006), and typhoon (Chou et al. 2017a). The GNSS TEC observations have been also derived as a global ionospheric map since 1998 for monitoring global ionospheric weather and climate (Schaer 1999; Mannucci et al. 1998; Hernandez-Pajares et al. 2009; Sun et al. 2017; Yao et al. 2018 and references therein).

On the other hand, the space-based GNSS radio occultation $(\mathrm{RO})$ technique can vertically scan the ionospheric density structure for better understanding of the global three-dimensional structure of ionosphere. FORMOSAT-3/COSMIC (Constellation Observing System for Meteorology, Ionosphere and Climate) (F3/C) satellite RO soundings have led to significant improvement of our understanding of the global morphology and variability of the dynamical Equatorial Ionospheric Anomaly (EIA) structures (e.g., Lin et al. 2007; Maruyama et al. 2016) and irregularities (e.g., Liu et al. 2016a; Chen et al. 2017a; Yu et al. 2018; Qiu et al. 2019).

Besides the effect from solar actives, perturbations from lower atmosphere [e.g., typhoon, walker circulation, and El Niño-Southern Oscillation (ENSO)] and surface (e.g., earthquake and tsunami) leave many of shape footprints messy on the ionosphere. The RO soundings also recorded the changes in stratospheric temperature during 
the 22 July 2009 total solar eclipse (Wang and Liu 2010), the ENSO effect on the quasi-biennial oscillation (QBO) from stratosphere to ionosphere (Das and Pan 2016; Sun et al. 2018a), and the earthquake/tsunami waves in ionosphere and stratosphere (Sun et al. 2016; Yan et al. 2018).

The sections below first briefly show studies of the effect of the solar activities (storm and eclipse) on the ionosphere. Then, we pay attention to the effect of the tropospheric (convections) and surface (earthquake/ tsunami) activities on the lower atmosphere to ionosphere observed by the ground- and space-based GNSS systems.

\section{lonospheric weather}

Figure 1 shows examples of ionospheric weather due to the solar storm and the moon shadow that can be comprehensively monitored by the GNSS systems. A solar storm that dumps energy into the Earth's upper

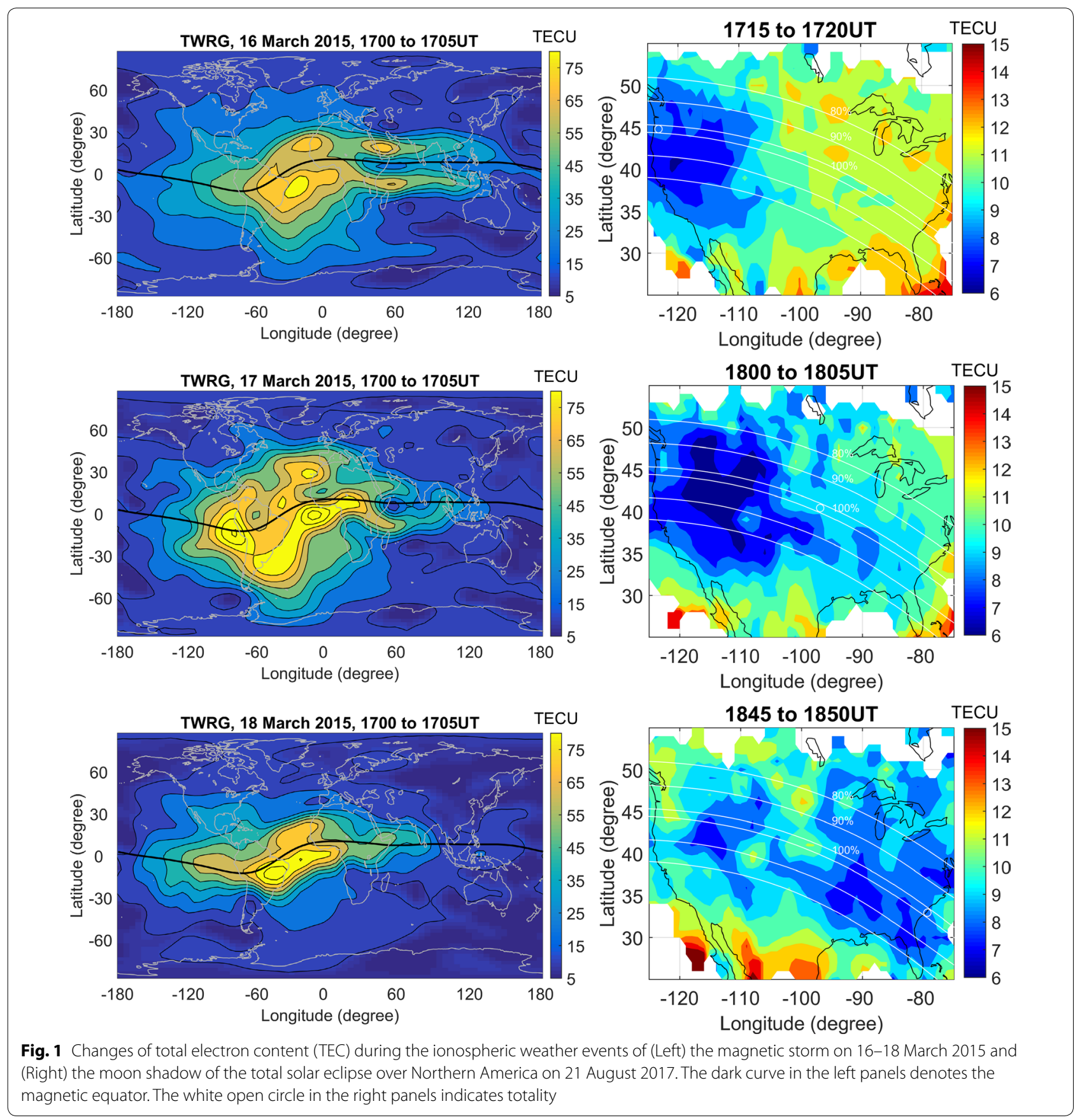


atmosphere can seriously impact ionospheric morphology and electron density (Ne) structure. A severe geomagnetic storm, named "St. Patrick's Day geomagnetic storm" that is one of the most intense storms during the weaker solar cycle 24, occurred on 17 March 2015. The minimum Dst value is less than $-200 \mathrm{nT}$ and $\mathrm{Kp}$ reaches a value of 8 (https://omniweb.gsfc.nasa.gov/). The left panels show the global features of the positive and negative ionospheric storms monitored by the Taiwan Realtime Global Ionospheric Map (TWR GIM). The TWR GIM is constructed from the global TEC observations, which included the data from $\sim 120$ ground-based GNSS stations and F3/C RO, using a spherical harmonic expansion and Kalman filter (Sun et al. 2017). The EIA consisted of two typical crests before the storm onset. The high TEC area much expanded from low to middle latitude in the first day after the storm onset (during the main phase period). The EIA crests became much weaker and the high TEC area significantly shrank toward the dip equator during the recovery phase for couple days. The evolution can be attributed to the disturbance of neutral atmosphere (Chen et al. 2016a) and electric fields (Kuai et al. 2016).

By contrast, the moon shadow masking the solar irradiation can also significantly change the ionospheric structure. Right panels of Fig. 1 show the reduction of $\sim 50 \%$ of TEC during the maximum obscuration period of the 21 August 2017 total solar eclipse (Sun et al. 2018b). Besides the significant losing rate of plasma in the lower part of ionosphere in the shadow area, it was surprising to see the density enhancement before and after the moon shadow. The temperature difference within and outside the moon shadow area can produce pressure gradients that drive thermospheric natural winds. Wu et al. (2018) conducted the global ionosphere-thermosphere model and showed that the divergence of horizontal winds drove the increase in Oxygen after the eclipse allowing an increase in the ionization rate. The assimilation result from Chen et al. (2019) showed stronger eastward electric fields around the magnetic equator region at the beginning of the solar eclipse (around the eastern boundary of moon shadow). The low-latitude eastward electric field may result from the sudden darkness at the termination region, like the eastward convection in the evening, and then further cause the early appearance of the EIA. Moreover, the pre-enhancement and sunset enhancement of TEC were observed during the 21 May 2012 annular solar eclipse and the other eclipses (Liu et al. 2019a and references therein).

In the present and future, the GNSS observations do a big favor for ionospheric data assimilation systems for constructing three-dimensional ionospheric Ne structure and updating neutral atmosphere (Lin et al. 2015, 2017;
Sun et al. 2015a, b; Chen et al. 2016b, 2017b; Hsu et al. 2018a, b). The data assimilation systems are constructed for nowcasting and forecasting of rapidly changing ionospheric weathers (Araujo-Pradere et al. 2006; Matsuo and Araujo-Pradere 2011; Lin et al. 2012; Komjathy et al. 2012; Sun et al. 2013; Chartier et al. 2016; Chen et al. 2016a, b, 2019), which is important for warning about the impact and improving the accuracy of the telecommunication and navigation systems.

\section{Troposphere activity}

Severe weather activities can not only affect troposphere (below $18 \mathrm{~km}$ altitude) but also modulate upper atmosphere. Nishioka et al. (2013) showed concentric waves and short-period oscillations in the ionosphere after an enhanced Fujita scale (EF-scale) 5 tornado in Moore, Oklahoma, on 20 May 2013 using dense ground-based GNSS TEC observations in North America. Chou et al. (2017a, b) analyzed the dense ground-based GNSS networks in Taiwan and Japan and reported that the super typhoons Meranti and Nepartak in 2016 induced concentric traveling ionospheric disturbance through the process of Perkin's instability. Song et al. (2017) reported the ground-based GNSS TEC detection of the ionospheric disturbances due to the typhoons Rammasum and Matmo in Southern China.

Longitudinal distribution of convection along the equator (e.g., Walker circulation) and its effect can induce the ionospheric Ne structure with wave number four at low and middle latitudes in a fix-local time frame. Lin et al. (2007) first showed the three-dimensional EIA wavefour structure recorded by the F3/C RO Ne soundings. The zonal wind DE3 (diurnal eastward wave 3 ) in the mesosphere-lower thermosphere (MLT) region has been attributed to the primary driver of the wave-four structure (Wan et al. 2008; Fang et al. 2009). The DE3 and SPW4 (stationary planetary wave 4) signatures in TEC comprise the largest portion of the wave-four structure (Pancheva and Mukhtarov 2010; Chang et al. 2013).

The El Niño-Southern Oscillation (ENSO) is a strong ocean-atmosphere coupled phenomenon that is considered to be a primary dynamic driver of the interannual variations in the troposphere. The tropospheric component of the ENSO is the abnormal distribution of convection along equator. The major pattern of the oceanic component of ENSO is the warm sea surface water moving across $180^{\circ} \mathrm{E}$ to the Eastern Pacific from the west that further drives the displacement of the strong convection area (Sun et al. 2014). Figure 2 shows that the tropopause height responds to the ENSO phases over the Niño 3.4 region $\left(5^{\circ} \mathrm{N}-5^{\circ} \mathrm{S}, 120^{\circ}-170^{\circ} \mathrm{W}\right)$ where the atmospheric convection anomaly highly correlates with the sea surface temperature anomaly. The Oceanic Niño 

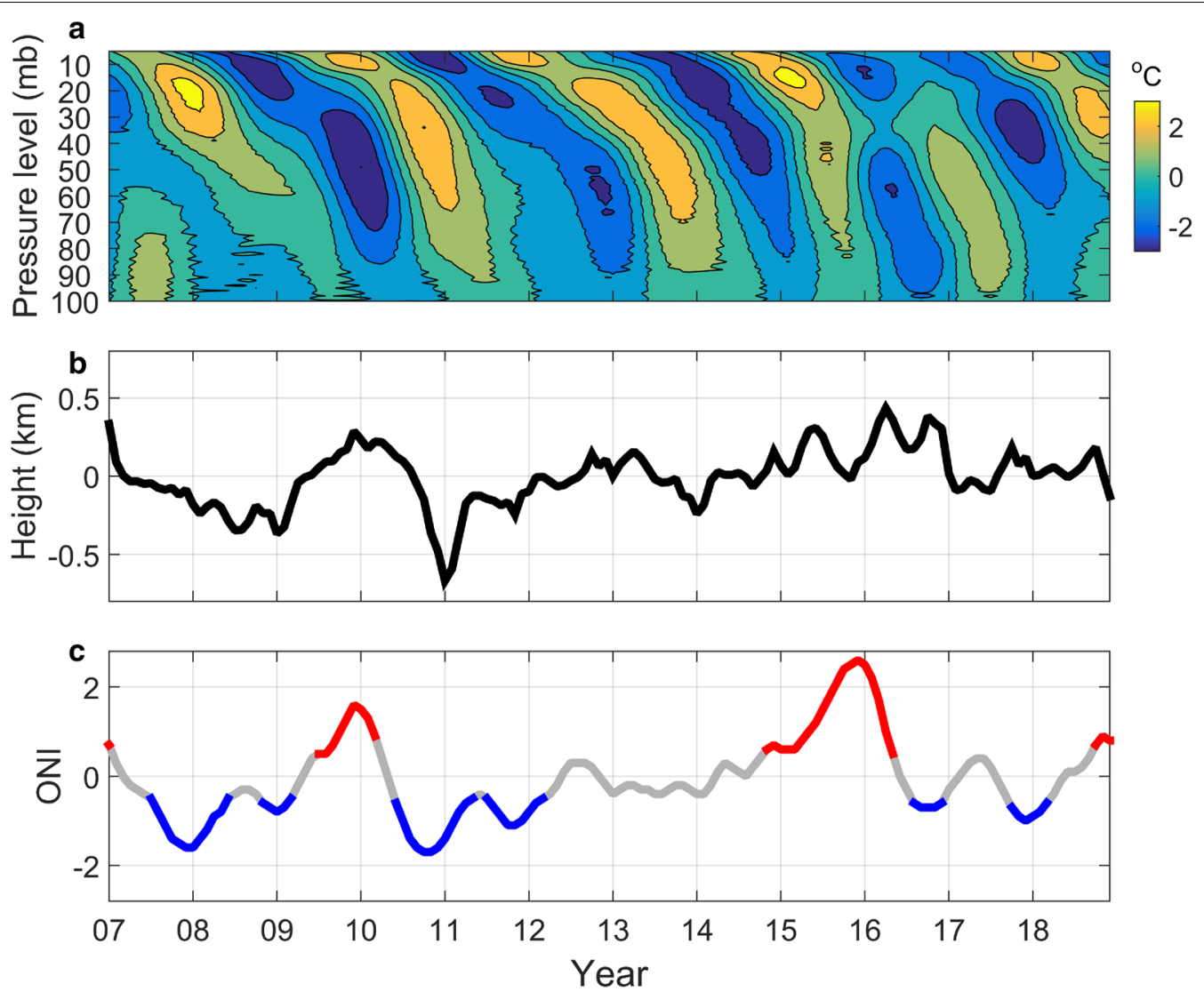

Fig. 2 a Quasi-biennial oscillation (QBO) and b tropopause height respond to El Niño-Southern Oscillation (ENSO) observed by the FORMOSAT-3/ COSMIC (F3/C) radio occultation ( $\mathrm{RO}$ ) technique. A band-pass filter with the cutoff period ranging from 18 to 34 months is applied to extract the QBO component from the RO temperature averaged within $5^{\circ} \mathrm{N}-5^{\circ} \mathrm{S}$ at each pressure level. $\mathbf{b}$ The departure of tropopause height from its mean annual cycle. The monthly tropopause height is averaged over the Niño 3.4 area $\left(5^{\circ} \mathrm{N}-5^{\circ} \mathrm{S}, 120^{\circ}-170^{\circ} \mathrm{W}\right)$. c Red and blue (exceeding the threshold of $\pm 0.5^{\circ} \mathrm{C}$ ) on the Oceanic Niño Index (ONI) indicates the ENSO warm and cold phases, respectively

Index (ONI) is derived from the sea surface temperature anomaly (SSTA) in the Niño 3.4 region. The tropopause observed by the $\mathrm{F} 3 / \mathrm{C} \mathrm{RO}$ is also collected above the Niño 3.4 region. The mean annual cycle was removed from the observation. The strong convection above the warm water raises up the tropopause by several hundred meters during the ENSO warm phases of 2009/2010 and 2015/2016.

The QBO, which normally shows a steady downward propagation of the westerly phase, is the major year-toyear variability in the stratosphere. Newman et al. (2016) reported the anomalous upward displacement of the westerly phase from $\sim 30$ to $15 \mathrm{hPa}$ pressure levels during the ENSO warm phase of $2015 / 2016$. The sudden disturbance of QBO is also recorded by the F3/C RO temperature, which is averaged within $\pm 5^{\circ} \mathrm{N}$ latitudes at each pressure level, during the ENSO warm phase of 2015/2016 (top panel of Fig. 2). Furthermore, it also has been known that the ENSO warm phases can shorten the QBO period not only in the stratosphere, but also in the
MLT region due to the interaction of broad-band atmospheric waves, tides, and background wind field (Das and Pan 2016; Sun et al. 2018a).

The ENSO is a periodic year-to-year variation with periods widely varying from 3 to 7 years in the atmosphere. An adaptive method such as the Hilbert-Huang transform (HHT) is appropriate for resolving the footprints of the highly non-stationary phenomenon left on the ionosphere (Chang et al. 2016). Figure 3a shows the annual cycle extracted from the F3/C TEC SPW4 amplitude using the multidimensional ensemble empirical mode decomposition of the HHT. The annual cycle was normalized by the residual that mainly contains the long-term trend of solar irradiance (Chang et al. 2016). Figure $3 \mathrm{~b}$ shows the departure of the normalized annual cycle from its mean annual cycle. The negative deviation corresponds to the ENSO warm phase in the 2009/2010 winter. The positive deviations correspond to the ENSO cold phases in the 2007/2008 and 2010/2011 winter in the Northern Hemisphere. The deviations may relate to 


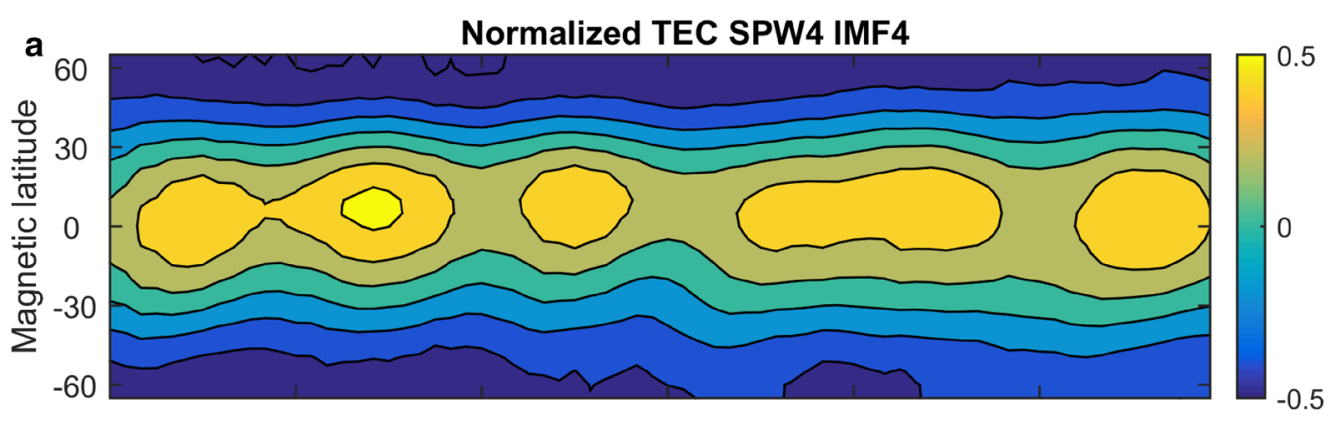

b

variation

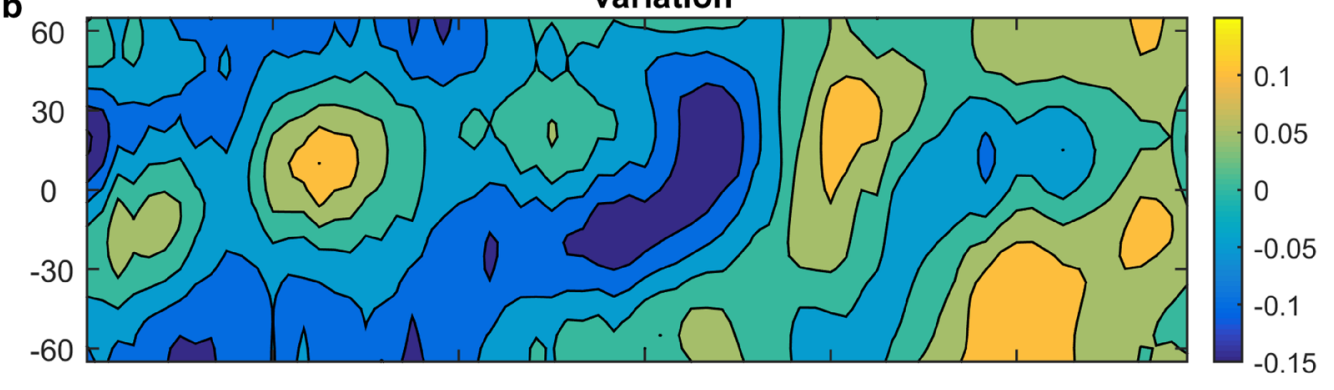

C

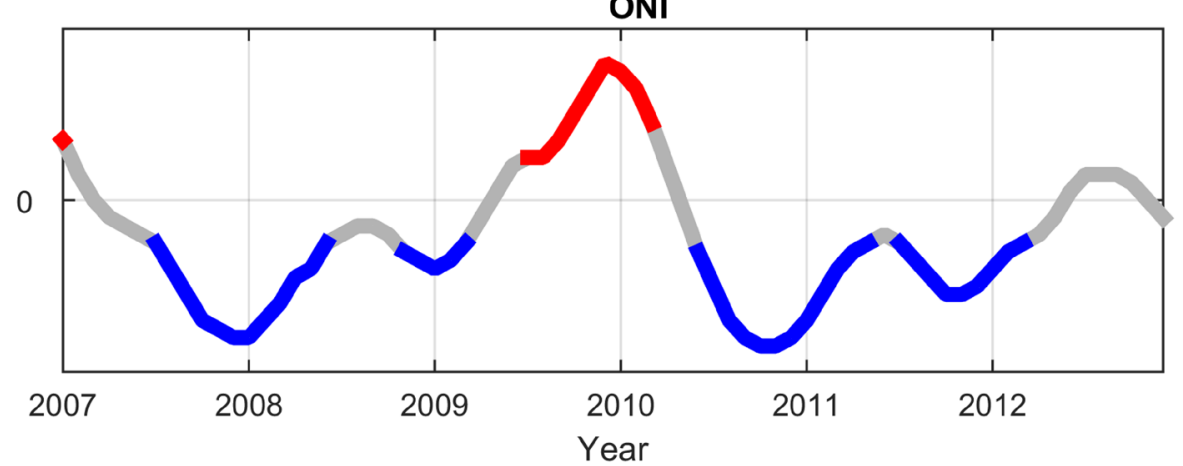

Fig. 3 The response of the annual component (IMF (intrinsic mode function) 4) of the ionospheric TEC (total electron content) SPW4 (stationary planetary wave 4) to ENSO. a Normalized annual component of the SWP4 amplitude. The normalized annual component is defined as the annual component being divided by its long-term trend at each latitude (seeing details from Chang et al. 2016). b The variation is the departure from the mean annual cycle of the normalized component. c ONI

the tides driven by the ENSO phases in the MLT region (Liu et al. 2017), and they could contribute to the QBO in the ionospheric tide/SPW (Sun et al. 2019). The complete story of ENSO effect on the ionosphere is far from complete and needs to be further examined. There is no agreement between the deviations and ENSO phases after 2012 due to the fact of the higher solar irradiance. Longer observations recorded during the lower solar activity period are required for examining the ENSO signal in the ionosphere.

The F3/C mission provided RO observation (2006 to present) during the solar cycle 24 . The follow-on FORMOSAT-7/COSMIC2 (F7/C2) mission was launched in June 2019, which continues the observations of electron density and scintillation allowing us to keep studying the response of ionospheric tide/SPW (Sun et al. 2019) and Sporadic E (Chang et al. 2018) to ENSO.

The ENSO is one of the phenomena that modulate convection and precipitation. We can expect that the other climate phenomena such as, Madden-Julian oscillation (Zeng et al. 2012), Pacific Decadal Oscillation (Sun et al. 2015b), and change of global precipitation trend (Wu and Lau 2016) can also modulate tides and stationary planetary waves in whole atmosphere. Moreover, the teleconnection of climate phenomena from the polar region, such as sudden stratospheric warming (Lin et al. 2019) and Arctic oscillation, to the global upper atmosphere and ionosphere can be also examined with the future RO mission. 


\section{Surface perturbations}

Sudden surface perturbations due to an earthquake or tsunami can induce seismo-traveling atmospheric disturbances (STADs) in the Earth's atmosphere. The observation of the ground-based GNSS TEC is an efficient technique for monitoring and examining the horizontal component of the STADs (e.g., Liu et al. 2011; Zhao and Hao 2015 and reference therein). Liu et al. (2019b) suggested that the dense ground-based GNSS receiver networks can be treated as space buoy arrays to monitor the atmospheric gravity wave induced by tsunami and earthquake. However, the favorable condition for detecting the STADs depends on the change of elevation angle of the GNSS satellites (Rolland et al. 2011). By contrast, the BeiDou Navigation Satellite System (BDS) satellites in a geosynchronous equatorial orbit (GEO) (at $\sim 35,000 \mathrm{~km}$ above the Earth's equator and following the direction of Earth's rotation) continuously measure TEC as a function of time but without the effect of change of elevation angle. A buoy floating on the water surface measures the wave period and amplitude. The BDS GEO satellites providing the $24 \times 7$ monitoring of ionospheric wavy structures over a certain location can be a perfect space buoy for detecting the tsunami traveling ionospheric disturbances.

On the other hand, the $\mathrm{RO}$ technique was applied to scan the vertical component of STADs in the recent years. Before the scientist applying the RO technique to detect the STADs, the ionosonde recorded the vertical structure of the lower part of ionosphere perturbed by the earthquake and tsunami (Leonard and Barnes 1965; Liu and Sun 2011; Maruyama et al. 2011, 2012). Liu et al. (2016b) employed concurrent and collocated measurements of seismometers, infrasonic systems, magnetometers, HF-CW (high-frequency continuous-wave) Doppler sounding systems, and GPS receivers and detected the vertical propagation of STADs due to the Tohoku earthquake over Taiwan.

The $\mathrm{RO}$ technique onboard a low earth orbit satellite can vertically scan the STADs from the lower to topside ionosphere. Astafyeva et al. (2011) identified the earthquake uplift area using the TEC observations from the F3/C RO and ground-based GNSS receivers after the 11 March 2011 Mw9.0 Tohoku earthquake. Sun et al. (2016) examined the F3/C RO Ne soundings and captured the wave front induced by the 25 April $2015 \mathrm{Mw}$ 7.8 Nepal earthquake. Yan et al. $(2018,2019)$ applied the wavelet analysis to show the acoustic resonance due to the 12 May 2008 Mw7.9 Wenchuan earthquake and the Tohoku earthquake/tsunami by analyzing dozens of ionospheric RO sounding profiles during the periods of $6 \mathrm{~h}$ before and after the earthquake initial rapture. Liu et al. (2019c) applied the Hilbert-Huang transform to derive the instantaneous wave number and amplitude of the fluctuations of F3/C RO Ne profiles and showed the vertical Ne fluctuations induced by underneath Rayleigh and tsunami waves of the Tohoku earthquake and their postwaves. Figure 4 is another example of the RO Ne fluctuations after the Mw8.8 Offshore Maule, Chile earthquake (epicenter: $35.8^{\circ} \mathrm{S}, 72.7^{\circ} \mathrm{W}$ ) and tsunami. The earthquake initial rapture occurred at 0334 LT (0634 UT) on 27 February 2010 . To avoid possible contamination of irregularities on the Ne observation at low latitude, the Ne profiles are collected during the periods of $3 \mathrm{~h}$ before (0034-0334 LT) and after (0334-0634 LT) the earthquake in the area of eastern South Pacific off Chile $\left(16^{\circ}\right.$ to $56^{\circ} \mathrm{S}, 73^{\circ}$ to $\left.120^{\circ} \mathrm{W}\right)$. The wavy structure with wavelength ranging from several to tens kilometers below $400 \mathrm{~km}$ altitude as shown in the Hilbert spectra is possible to be the longlasting tail or atmospheric resonance after the wave front passing through the atmosphere (Yan et al. 2018).

Besides the ionospheric disturbances, the RO observation can also record the STADs in the lower atmosphere. Yan et al. (2018) analyzed the F3/C atmospheric refractivity index and reported that the 2011 Tohoku earthquake/ tsunami can perturb the vertical structures of not only the ionosphere, but also the stratosphere with vertical wavelength of several kilometers. The RO-recorded vertical component of STADs allows a more comprehensive understanding of excitation, propagation, and dissipation of earthquake/tsunami-induced waves in the whole atmosphere. The wave detection in the lower atmosphere can benefit to improve earthquake and tsunami warning systems.

\section{Summary}

The ground- and space-based GNSS systems are efficient and well-established techniques for measuring ionospheric structures in both horizontal and vertical directions that help data assimilation systems for nowcasting and forecasting of ionospheric weather all over the globe. The dense radio occultation (RO) soundings from FORMOSAT-3/COSMIC (F3/C) (2006 April to present) and the follow-on FORMOSAT-7/COSMIC2 (F7/C2) mission (since 2019 July) can provide thousands of soundings per day for more than 20 years that is pertinent to the ongoing study attempting to establish the long-term change in the troposphere to the upper atmosphere. We can expect that the follow-on RO mission can capture the ground perturbation not only in the ionosphere, but also in the lower atmosphere. The GNSS systems bring us a holistic view of dynamic interaction between the Earth's spheres and help us to seek a deeper understanding of our solar-terrestrial environment. 

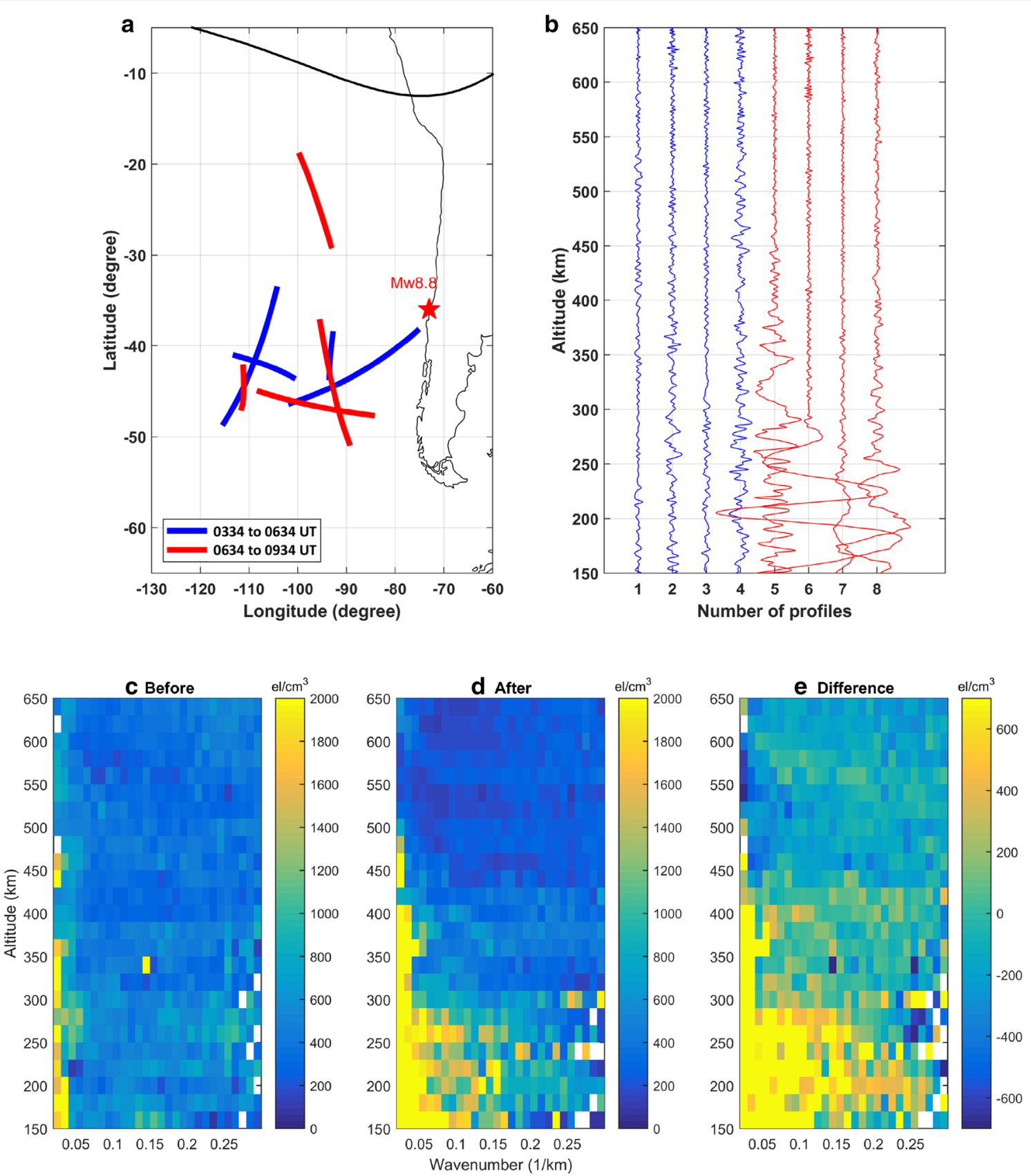

Fig. 4 a Distributions of the tangent points of the F3/C RO electron density ( $\mathrm{Ne}$ ) soundings in the area of eastern South Pacific off Chile during the periods of $3 \mathrm{~h}$ before (blue) and after (red) the 27 February 2010 Mw8.8 Offshore Maule, Chile earthquake. $\mathbf{b}$ Fluctuations of the Ne profiles before (blue) and after (red) the earthquake. The trend determined by the empirical model decomposition has been removed from the raw profiles for showing the fluctuations. The Hilbert spectra of the fluctuations $\mathbf{c} 3 \mathrm{~h}$ before and $\mathbf{d} 3 \mathrm{~h}$ after the earthquake. $\mathbf{e}$ The difference between the two spectra $(\mathbf{d}-\mathbf{c})$

\section{Acknowledgements}

I appreciate the invitation from AOGS to present the results in Kamide Lecture for the Solar-Terrestrial section.

\section{Authors' contributions}

YYS compose the manuscript. The author read and approved the final manuscript.

\section{Funding}

This research was supported by NSFC (National Nature Science Foundation of China), Grant Number 41804154 and the Fundamental Research Funds for the Central Universities, China University of Geosciences (Wuhan), Grant Number 2018022. 


\section{Availability of data and materials}

The International GNSS Service (IGS) (http://garner.ucsd.edu/) and Continuously Operating Reference Station (CORS) (https://geodesy.noaa.gov/CORS/ data.shtml) provide the ground-based GNSS data. The FORMOSAT-3/COSMIC observations are downloaded from ftp://cdaac-ftp.cosmic.ucar.edu. The Oceanic Niño Index (ONI) is obtained from http://www.cpc.noaa.gov/produ cts/analysis_monitoring/ensostuff/ensoyears.shtml.

\section{Competing interests}

The author declares no competing interests.

Received: 31 August 2019 Accepted: 4 November 2019

Published online: 14 November 2019

\section{References}

Araujo-Pradere EA, Fuller-Rowell TJ, Spencer PSJ (2006) Consistent features of TEC changes during ionospheric storms. J Atmos Solar Terr Phys 68(16):1834-1842. https://doi.org/10.1016/j.jastp.2006.06.004

Astafyeva E, Lognonne P, Rolland L (2011) First ionospheric images of the seismic fault slip on the example of the Tohoku-oki earthquake. Geophys Res Lett. https://doi.org/10.1029/2011GL049623

Chang LC, Lin CH, Yue J, Liu JY, Lin JT (2013) Stationary planetary wave and nonmigrating tidal signatures in ionospheric wave 3 and wave 4 variations in 2007-2011 FORMOSAT-3/COSMIC observations. J Geophys Res Space Phys 118(10):6651-6665. https://doi.org/10.1002/jgra.50583

Chang LC, Sun YY, Yue J, Wang JC, Chien SH (2016) Coherent seasonal, annual, and quasi-biennial variations in ionospheric tidal/SPW amplitudes. J Geophys Res Space Phys 121(7):6970-6985. https://doi.org/10.1002/2015J A022249

Chang LC, Chiu PY, Salinas CCJH, Chen SP, Duann Y, Liu JY et al (2018) On the relationship between $\mathrm{E}$ region scintillation and ENSO observed by FORMOSAT-3/COSMIC. J Geophys Res Space Phys 123(5):4053-4065. https:// doi.org/10.1029/2018ja025299

Chartier AT, Matsuo T, Anderson JL, Collins N, Hoar TJ, Lu G et al (2016) Ionospheric data assimilation and forecasting during storms. J Geophys Res Space Phys 121(1):764-778. https://doi.org/10.1002/2014ja020799

Chen CH, Lin CH, Matsuo T, Chen WH (2016a) lonosphere data assimilation modeling of 2015 St. Patrick's Day geomagnetic storm. J Geophys Res Space Phys 121(11):11549-11559. https://doi.org/10.1002/2016ja023346

Chen CH, Lin CH, Matsuo T, Chen WH, Lee IT, Liu JY et al (2016b) lonospheric data assimilation with thermosphere-ionosphere-electrodynamics general circulation model and GPS-TEC during geomagnetic. J Geophys Res Space Phys 121(6):5708-5722. https://doi.org/10.1002/2015ja021787

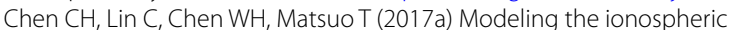
prereversal enhancement by using coupled thermosphere-ionosphere data assimilation. Geophys Res Lett 44(4):1652-1659. https://doi. org/10.1002/2016GL071812

Chen SP, Bilitza D, Liu JY, Caton R, Chang LC, Yeh WH (2017b) An empirical model of L-band scintillation $\mathrm{S} 4$ index constructed by using FORMOSAT-3/COSMIC data. Adv Space Res 60(5):1015-1028. https://doi. org/10.1016/j.asr.2017.05.031

Chen CH, Lin CHC, Matsuo T (2019) lonospheric responses to the 21 August 2017 solar eclipse by using data assimilation approach. Progr Earth Planetary Sci. https://doi.org/10.1186/s40645-019-0263-4

Chou MY, Lin CCH, Yue J, Chang LC, Tsai HF, Chen CH (2017a) Mediumscale traveling ionospheric disturbances triggered by Super Typhoon Nepartak (2016). Geophys Res Lett 44(15):7569-7577. https://doi. org/10.1002/2017gl073961

Chou MY, Lin CCH, Yue J, Tsai HF, Sun YY, Liu JY et al (2017b) Concentric traveling ionosphere disturbances triggered by Super Typhoon Meranti (2016). Geophys Res Lett 44(3):1219-1226. https://doi.org/10.1002/2016g 1072205

Das U, Pan CJ (2016) Equatorial atmospheric Kelvin waves during El Niño episodes and their effect on stratospheric QBO. Sci Total Environ 544:908918. https://doi.org/10.1016/j.scitotenv.2015.12.009

Fang TW, Kil H, Millward G, Richmond AD, Liu JY, Oh SJ (2009) Causal link of the wave-4 structures in plasma density and vertical plasma drift in the low-latitude ionosphere. J Geophys Res Space Phys 114:A10315. https:// doi.org/10.1029/2009ja014460
Hernandez-Pajares M, Juan JM, Sanz J, Orus R, Garcia-Rigo A, Feltens J et al (2009) The IGS VTEC maps: a reliable source of ionospheric information since 1998. J Geodesy 83(3-4):263-275. https://doi.org/10.1007/s0019 0-008-0266-1

Hsu CT, Matsuo T, Liu JY (2018a) Impact of assimilating the FORMOSAT-3/ COSMIC and FORMOSAT-7/COSMIC-2 RO data on the midlatitude and low-latitude ionospheric specification. Earth Space Sci 5(12):875-890. https://doi.org/10.1029/2018EA000447

Hsu CT, Matsuo T, Yue X, Fang TW, Fuller-Rowell T, Ide K et al (2018b) Assessment of the impact of FORMOSAT-7/COSMIC-2 GNSS RO observations on midlatitude and low-latitude ionosphere specification: observing system simulation experiments using ensemble square root filter. J Geophys Res Space Phys 123(3):2296-2314. https://doi.org/10.1002/2017JA025109

Kamide Y, Chian ACL (2007) Handbook of the solar-terrestrial environment. Springer, Berlin. https://doi.org/10.1007/978-3-540-46315-3

Komjathy A, Galvan DA, Stephens P, Butala MD, Akopian V, Wilson B et al (2012) Detecting ionospheric TEC perturbations caused by natural hazards using a global network of GPS receivers: the Tohoku case study. Earth Planets Space 64(12):1287-1294. https://doi.org/10.5047/eps.2012.08.003

Kuai JW, Liu LB, Liu J, Sripathi S, Zhao BQ, Chen YD et al (2016) Effects of disturbed electric fields in the low-latitude and equatorial ionosphere during the 2015 St. Patrick's Day storm. J Geophys Res Space Phys 121(9):9111-9126. https://doi.org/10.1002/2016ja022832

Leonard RS, Barnes RA (1965) Observations of ionospheric disturbances following the Alaska earthquake. J Geophys Res 70:1250-1253. https://doi. org/10.1029/JZ070i005p01250

Lin CH, Wang W, Hagan ME, Hsiao CC, Immel TJ, Hsu ML et al (2007) Plausible effect of atmospheric tides on the equatorial ionosphere observed by the FORMOSAT-3/COSMIC: three-dimensional electron density structures. Geophys Res Lett. https://doi.org/10.1029/2007gl029265

Lin CY, Liu JY, Lin CH, Sun YY, Araujo-Pradere EA, Kakinami Y (2012) Using the $I R I$, the MAGIC model, and the co-located ground-based GPS receivers to study ionospheric solar eclipse and storm signatures on July 22, 2009. Earth Planets Space 64(6):513-520. https://doi.org/10.5047/ eps.2011.08.016

Lin CY, Matsuo T, Liu JY, Lin CH, Tsai HF, Araujo-Pradere EA (2015) lonospheric assimilation of radio occultation and ground-based GPS data using non-stationary background model error covariance. Atmos Meas Techn 8(1):171-182. https://doi.org/10.5194/amt-8-171-2015

Lin CY, Matsuo T, Liu JY, Lin CH, Huba JD, Tsai HF et al (2017) Data assimilation of ground-based gps and radio occultation total electron content for global ionospheric specification. J Geophys Res Space Phys 122(10):10876-10886. https://doi.org/10.1002/2017JA024185

Lin JT, Lin CH, Lin CY, Pedatelle NM, Rajesh PK, Matsuo T et al (2019) Revisiting the modulations of ionospheric solar and lunar migrating tides during the 2009 stratospheric sudden warming by using global ionosphere specification. Space Weather Int J Res Appl 17(5):767-777. https://doi. org/10.1029/2019SW002184

Liu JY, Sun YY (2011) Seismo-traveling ionospheric disturbances of ionograms observed during the 2011 M-w 9.0 Tohoku Earthquake. Earth Planets Space 63(7):897-902. https://doi.org/10.5047/eps.2011.05.017

Liu JY, Tsai YB, Chen SW, Lee CP, Chen YC, Yen HY et al (2006) Giant ionospheric disturbances excited by the M93 Sumatra earthquake of 26 December 2004. Geophys Res Lett. https://doi.org/10.1029/2005gl023963

Liu JY, Sun YY, Kakinami Y, Chen CH, Lin CH, Tsai HF (2011) Bow and stern waves triggered by the Moon's shadow boat. Geophys Res Lett. https:// doi.org/10.1029/2011GL048805

Liu JY, Chen CH, Sun YY, Chen CH, Tsai HF, Yen HY et al (2016a) The vertical propagation of disturbances triggered by seismic waves of the 11 March 2011 M9.0 Tohoku earthquake over Taiwan. Geophys Res Lett 43(4):1759_ 1765. https://doi.org/10.1002/2015gl067487

Liu JY, Chen SP, Yeh WH, Tsai HF, Rajesh PK (2016b) Worst-case GPS scintillations on the ground estimated from radio occultation observations of FORMOSAT-3/COSMIC during 2007-2014. Surv Geophys 37(4):791-809. https:// doi.org/10.1007/s10712-015-9355-X

Liu HX, Sun YY, Miyoshi Y, Jin H (2017) ENSO effects on MLT diurnal tides: a 21 year reanalysis data-driven GAIA model simulation. J Geophys Res Space Phys 122(5):5539-5549. https://doi.org/10.1002/2017JA024011

Liu JY, Yang SS, Rajesh PK, Sun YY, Chum J, Pan CJ et al (2019a) Ionospheric response to the 21 May 2012 annular solar eclipse over Taiwan. J Geophys Res Space Phys 124(5):3623-3636. https://doi.org/10.1029/2018JA025928 
Liu JY, Lin CY, Tsai YL, Liu TC, Hattori K, Sun YY, Wu TR (2019b) lonospheric GNSS total electron content for tsunami warning. J Earthq Tsunami. https://doi. org/10.1142/s1793431119410070

Liu JY, Chen CY, Sun YY, Lee IT, Chum J (2019c) Fluctuations on vertical profiles of the ionospheric electron density perturbed by the March 11, 2011 M9.0 Tohoku earthquake and tsunami. GPS Sol. https://doi.org/10.1007/ s10291-019-0866-7

Mannucci AJ, Wilson BD, Yuan DN, Ho CH, Lindqwister UJ, Runge TF (1998) A global mapping technique for GPS-derived ionospheric total electron content measurements. Radio Sci 33(3):565-582. https://doi. org/10.1029/97RS02707

Maruyama T, Tsugawa T, Kato H, Saito A, Otsuka Y, Nishioka M (2011) lonospheric multiple stratifications and irregularities induced by the 2011 off the Pacific coast of Tohoku Earthquake. Earth Planets Space 63(7):869873. https://doi.org/10.5047/eps.2011.06.008

Maruyama T, Tsugawa T, Kato H, Ishii M, Nishioka M (2012) Rayleigh wave signature in ionograms induced by strong earthquakes. J Geophys Res Space Phys. https://doi.org/10.1029/2012ja017952

Maruyama N, Sun YY, Richards PG, Middlecoff J, Fang TW, Fuller-Rowell TJ et al (2016) A new source of the midlatitude ionospheric peak density structure revealed by a new ionosphere-plasmasphere model. Geophys Res Lett 43(6):2429-2435. https://doi.org/10.1002/2015GL067312

Matsuo T, Araujo-Pradere EA (2011) Role of thermosphere-ionosphere coupling in a global ionospheric specification. Radio Sci. https://doi. org/10.1029/2010rs004576

Newman PA, Coy L, Pawson S, Lait LR (2016) The anomalous change in the QBO in 2015-2016. Geophys Res Lett 43:8791-8797. https://doi. org/10.1002/2016GL070373

Nishioka M, Tsugawa T, Kubota M, Ishii M (2013) Concentric waves and short-period oscillations observed in the ionosphere after the 2013 Moore EF5 tornado. Geophys Res Lett 40(21):5581-5586. https://doi. org/10.1002/2013gl057963

Pancheva D, Mukhtarov P (2010) Strong evidence for the tidal control on the longitudinal structure of the ionospheric F-region. Geophys Res Lett. https://doi.org/10.1029/2010gl044039

Qiu LH, Zuo XM, Yu T, Sun YY, Qi YF (2019) Comparison of global morphologies of vertical ion convergence and sporadic E occurrence rate. Adv Space Res 63(11):3606-3611. https://doi.org/10.1016/j.asr.2019.02.024

Rolland LM, Lognonne P, Munekane H (2011) Detection and modeling of Rayleigh wave induced patterns in the ionosphere. J Geophys Res Space Phys. https://doi.org/10.1029/2010JA016060

Schaer S (1999) Mapping and predicting the earths ionosphere using the global positioning system. Ph.D. thesis, Ph.D. dissertation. University of Bern, Bern

Song Q, Ding F, Zhang XX, Mao T (2017) GPS detection of the ionospheric disturbances over China due to impacts of Typhoons Rammasum and Matmo. J Geophys Res Space Phys 122(1):1055-1063. https://doi. org/10.1002/2016ja023449

Sun YY, Matsuo T, Araujo-Pradere EA, Liu JY (2013) Ground-based GPS observation of SED-associated irregularities over CONUS. J Geophys Res Space Phys 118(5):2478-2489. https://doi.org/10.1029/2012ja018103

Sun YY, Liu JY, Tsai HF, Lin CH, Kuo YH (2014) The equatorial El Nino-Southern oscillation signatures observed by FORMOSAT-3/COSMIC from July 2006 to January 2012. Terr Atmos Oceanic Sci 25(4):545-558. https://doi. org/10.3319/Tao.2014.02.13.01(a)

Sun YY, Chen CH, Liu JY, Wang CH, Chen DL (2015a) Instantaneous phase shift of annual subsurface temperature cycles derived by the Hilbert-Huang transform. J Geophys Res Space Phys 120(5):1670-1677. https://doi. org/10.1002/2014jd022574

Sun YY, Matsuo T, Maruyama N, Liu JY (2015b) Field-aligned neutral wind bias correction scheme for global ionospheric modeling at midlatitudes by assimilating FORMOSAT-3/COSMIC hmF(2) data under geomagnetically quiet conditions. J Geophys Res Space Phys 120(4):3130-3149. https:// doi.org/10.1002/2014JA020768

Sun YY, Liu JY, Lin CY, Tsai HF, Chang LC, Chen CY et al (2016) lonospheric F-2 region perturbed by the 25 April 2015 Nepal earthquake. J Geophys Res Space Phys 121(6):5778-5784. https://doi.org/10.1002/2015ja022280

Sun YY, Liu JY, Tsai HF, Krankowski A (2017) Global ionosphere map constructed by using total electron content from ground-based GNSS receiver and FORMOSAT-3/COSMIC GPS occultation experiment. GPS Sol 21(4):1583-1591. https://doi.org/10.1007/s10291-017-0635-4

Sun YY, Liu HX, Miyoshi Y, Liu LB, Chang LRC (2018a) El Nino-Southern Oscillation effect on quasi-biennial oscillations of temperature diurnal tides in the mesosphere and lower thermosphere. Earth Planets Space. https:// doi.org/10.1186/s40623-018-0832-6

Sun YY, Liu JY, Lin CCH, Lin CY, Shen MH, Chen CH et al (2018b) lonospheric bow wave induced by the moon shadow ship over the continent of United States on 21 August 2017. Geophys Res Lett 45(2):538-544. https ://doi.org/10.1002/2017gl075926

Sun YY, Liu H, Miyoshi Y, Chang LC, Liu L (2019) El Niño - Southern Oscillation effect on ionospheric tidal/SPW amplitude in 2007-2015 FORMOSAT-3/ COSMIC observations. Earth Planets Space 71:35. https://doi.org/10.1186/ s40623-019-1009-7

Wan W, Liu L, Pi X, Zhang ML, Ning B, Xiong J et al (2008) Wavenumber-4 patterns of the total electron content over the low latitude ionosphere. Geophys Res Lett. https://doi.org/10.1029/2008gl033755

Wang KY, Liu CH (2010) Profiles of temperature responses to the 22 July 2009 total solar eclipse from FORMOSAT-3/COSMIC constellation. Geophys Res Lett. https://doi.org/10.1029/2009GL040968

Wu HTJ, Lau WKM (2016) Detecting climate signals in precipitation extremes from TRMM (1998-2013) Increasing contrast between wet and dry extremes during the "global warming hiatus". Geophys Res Lett 43(3):1340-1348. https://doi.org/10.1002/2015gl067371

Wu C, Ridley AJ, Goncharenko L, Chen G (2018) GITM-data comparisons of the depletion and enhancement during the 2017 solar eclipse. Geophys Res Lett 45(8):3319-3327. https://doi.org/10.1002/2018GL077409

Yan XX, Sun YY, Yu T, Liu JY, Qi YF, Xia CL et al (2018) Stratosphere perturbed by the 2011 Mw90 Tohoku earthquake. Geophys Res Lett 45(19):1005010056. https://doi.org/10.1029/2018gl079046

Yan X, Yu T, Sun YY, Xia C, Zuo X, Yang N, Qi Y, Wang J (2019) Vertical structure of the ionospheric response following the Mw 79 Wenchuan earthquake on 12 May 2008. Pure Appl Geophys. https://doi.org/10.1007/s0002 4-019-02175-7

Yao YB, Liu L, Kong J, Zhai CZ (2018) Global ionospheric modeling based on multi-GNSS, satellite altimetry, and Formosat-3/COSMIC data. GPS Sol. https://doi.org/10.1007/s10291-018-0770-6

Yu T, Miyoshi Y, Xia CL, Zuo XM, Yan XX, Yang N et al (2018) Solar dependence of equatorial $f$ region irregularities observed by COSMIC radio occultations. J Geophys Res Space Phys 123(11):9775-9787. https://doi. org/10.1029/2018JA025936

Zeng Z, Ho SP, Sokolovskiy S, Kuo YH (2012) Structural evolution of the Madden-Julian Oscillation from COSMIC radio occultation data. J Geophys Res Atmos. https://doi.org/10.1029/2012jd017685

Zhao BQ, Hao YQ (2015) lonospheric and geomagnetic disturbances caused by the 2008 Wenchuan earthquake: a revisit. J Geophys Res Space Phys 120(7):5758-5777. https://doi.org/10.1002/2015JA021035

\section{Publisher's Note}

Springer Nature remains neutral with regard to jurisdictional claims in published maps and institutional affiliations. 